\title{
Review
}

\section{Biological Basis for the Use of Botanicals in Osteoarthritis and Rheumatoid Arthritis: A Review}

\author{
Salahuddin Ahmed, Jeremy Anuntiyo, Charles J. Malemud and Tariq M. Haqqi \\ Department of Medicine, Division of Rheumatic Diseases, Case Western Reserve University School of Medicine, \\ 10900 Euclid Avenue, Cleveland, OH-44106-4946, USA
}

\begin{abstract}
Osteoarthritis $(\mathrm{OA})$ of the knee and hip is a debilitating disease affecting more women than men and the risk of developing OA increases precipitously with aging. Rheumatoid arthritis (RA), the most common form of inflammatory joint diseases, is a disease of unknown etiology and affects $\sim 1 \%$ of the population worldwide, and unlike OA, generally involves many joints because of the systemic nature of the disease. Non-steroidal anti-inflammatory drugs (NSAIDs) are the first drugs of choice for the symptomatic treatment of both OA and RA. Because of the risks associated with the use of NSAIDs and other limitations, the use of alternative therapies, such as acupuncture and medicinal herbs, is on the rise and according to reports $\sim 60-90 \%$ of dissatisfied arthritis patients are likely to seek the option of complementary and alternative medicine (CAM). This paper reviews the efficacy of some of the common herbs that have a history of human use and their anti-inflammatory or antiarthritic properties have been evaluated in animal models of inflammatory arthritis, in studies employing well defined and widely accepted in vitro models that use human chondrocytes/cartilage explants or in clinical trials. Available data suggests that the extracts of most of these herbs or compounds derived from them may provide a safe and effective adjunctive therapeutic approach for the treatment of OA and RA. This, in turn, argues for trials to establish efficacy and optimum dosage of these compounds for treating human inflammatory and degenerative joint diseases.
\end{abstract}

Keywords: cats claw - curcumin - ginger - green tea - inflammation - osteoarthritis - rheumatoid arthritis

\section{Introduction}

Osteoarthritis (OA) of the knee and hip is a debilitating disease and the risk increases precipitously with aging. The severity of OA varies from person to person, but the consonant clinical signs include pain, reduced range of motion, inflammation and deformity $(1,2)$. OA and other rheumatic diseases currently affect $>43$ million Americans with the number expected to increase to an estimated 60 million by the year $2020(3,4)$. The high prevalence of $\mathrm{OA}$ with its associated loss of joint function results in expensive and long-term conventional therapies that poses a significant socioeconomic burden. This fact

For reprints and all correspondence: Dr Tariq M. Haqqi, Department of Medicine, Division of Rheumatic Diseases, Case Western Reserve University School of Medicine, 2109 Adelbert Road, Cleveland, OH-44106-4946, USA. Tel: +1-216-368-1374; Fax: +1-216-368-1332; E-mail: txh5@case.edu alone makes OA a significant health and economic challenge. When clinically evident, OA is characterized by joint pain, tenderness, limitation of movement, crepitus, occasional effusion and variable degrees of inflammation without systemic effects. Although not a traditional inflammatory disease, symptoms of local inflammation and synovitis are present in many patients of OA and also seen in animal models of OA [reviewed in (5)]. The presence of elevated levels of proinflammatory cytokines IL- 1 and TNF- $\alpha$ has been demonstrated in OA synovial fluid and it has been shown that proinflammatory cytokines can stimulate the expression of inflammatory mediators and matrix degrading metalloproteinases in an arthritic joint [(6,7) and references therein]. Pharmacological management of $\mathrm{OA}$ includes the administration of analgesics and non-steroidal anti-inflammatory drugs (NSAIDs), but their use does not provide adequate pain relief in some patients.

(C) The Author (2005). Published by Oxford University Press. All rights reserved.

The online version of this article has been published under an open access model. Users are entitled to use, reproduce, disseminate, or display the open access version of this article for non-commercial purposes provided that: the original authorship is properly and fully attributed; the Journal and Oxford University Press are attributed as the original place of publication with the correct citation details given; if an article is subsequently reproduced or disseminated not in its entirety but only in part or as a derivative work this must be clearly indicated. For commercial re-use, please contact journals.permissions@oupjournals.org 
Inflammatory joint diseases, of which rheumatoid arthritis (RA) represents the most common form, is a chronic and systemic inflammatory disease of unknown etiology and is marked by synovial hyperplasia with local invasion of bone and cartilage leading to joint destruction $(8,9)$. RA affects $\sim 1 \%$ of the adult population with more women being afflicted than men $[(3,10)$ and references therein]. Recent reports suggest that patients with RA not only have a higher chronic disease burden [(11,12) and references therein] but may also have increased morbidity and mortality from cardiovascular disease compared with persons without RA (13). RA pathogenesis is regulated by proinflammatory cytokines such as IL-1 and TNF- $\alpha$ that activate a broad array of intracellular signal transduction mechanisms (14-16). In RA, migration of leukocytes into the synovial tissue (ST) occurs. These leukocytes and other cells in the ST, particularly RA ST fibroblasts, produce several mediators of inflammation, including chemokines-chemotactic cytokines that recruit leukocytes to the inflamed joint and also play a role in angiogenesis [(17) and references therein].

Like OA, current treatment modalities for RA are mostly symptomatic although recently it has been suggested that use of disease-modifying antirheumatic drugs (DMARDs) has led to important gains in our overall ability to treat RA patients, resulting in a better health status for patients with RA (18). The value of DMARDs for treating OA or RA is also limited by their side effects and the fact that they are more expensive to use than traditional NSAIDs. The major side effects of NSAIDs are their propensity to cause stomach ulcers, GI bleeding and perforations. Although a new class of NSAIDs - the specific inhibitors of COX-2-was developed, these drugs have similar efficacy as the general NSAIDs but are safer with respect to gastrointestinal toxicity. However, some of these COX-2 inhibitors were recently withdrawn from the market or ordered by the United States Food and Drug Administration (FDA) to have a black box warning on the label because of concerns that their long-term use may increase the risk of stroke and heart attack.

However, despite optimal use of currently available antirheumatic agents, most RA patients live with chronic pain and severe functional decline because these therapies focus primarily on preventing joint inflammation and soft tissue swelling, but are not effective in preventing cartilage breakdown and the joint destruction associated with RA.

Recently, efforts have been focused on using the class of drugs called biologics (antibodies or soluble receptors for IL-1, IL- 6 and TNF- $\alpha$ ) for the treatment of OA and RA. Although these agents reduce inflammation and joint destruction, their long-term risks and benefits are not yet clear. Additionally, higher costs and the findings that they are not effective universally and severe side effects such as life-threatening infections and increased risk of malignancies limit the use of such agents in many populations (19-23). Thus, a final assessment on the use of biologics for the treatment of RA or OA, particularly with regard to risk of infections, malignancies and autoantibody production has to be carefully monitored.
Because of these and other limitations, the use of complementary and alternative medicine (CAM) therapies, such as acupuncture and extracts of medicinal herbs, is on the rise and according to reports $\sim 60-90 \%$ of dissatisfied arthritis patients are likely to seek the option of CAM therapy $(24,25)$. While most of the rheumatologists and other clinicians are skeptical of CAM therapies, patients who use CAM appear to be satisfied with the self-care approach. This self-satisfaction is mostly based on the notion that since these herbs and plants are found in nature, remedies derived from them must be safe. However, the long-term safety and efficacy of most of the herbal preparations commonly promoted as antiarthritic have not been established by placebo-controlled randomized trials either in OA or RA patients and indeed some of these may even interfere with the ongoing treatments. Therefore, it is imperative that scientific evidence regarding the safety and efficacy of herbal preparations commonly used by arthritis patients be presented to both the physicians and the patients helping them in making informed decisions. The objective of this review is to summarize the currently available information on selective herbal preparations that are commonly consumed by arthritis patients.

\section{Historical Perspective}

Herbal medicine is the root of various traditional medicine systems around the world. Botanicals are a chemical source that directly provides $\sim 25 \%$ of currently used crude drugs, with another $25 \%$ derived from chemically altered natural products (26). Various traditional medicine systems around the world, including ancient Chinese medicinal system, Indian medicinal system (composed of two major branches-Unani and Ayurveda) and Amazonian ethnomedicine, rely heavily on herbs for health preservation and healing. Herbal medicines have been described in traditional texts and used as antimicrobial, anti-inflammatory and antiviral medicine for the cure of allergies, RA, infections, wound healing and fever (27). Arthritis (both OA and RA) is one of the foremost diseases for which patient seeks the CAM option $(28,29)$. Because there is little evidence about the long-term effects of currently available traditional medicines and its associated adverse effects, the American College of Rheumatology recommends the careful use of dietary supplements and herbal medicines during early stages of treatment or disease development to limit the degree of joint destruction.

It is no surprise, then, that the use of alternative medicine, such as botanicals and nutritional supplements, has become popular with arthritis patients and is on the rise. An increasing number of people in the United States, as many as $42 \%$ use complementary or alternative medicine approaches to help meet their personal health problems $(29,30)$. This review describes the currently available scientific evidence that regarding the efficacy and toxic effects, if known, of Camellia sinensis (green tea) (Fig. 1A), Uncaria tomentosa (cat's claw) (Fig. 1B), Tripterygium wilfordii Hook F (Fig. 1C), Curcuma longa (turmeric) (Fig. 1D) and Zingiber officinale (ginger) 


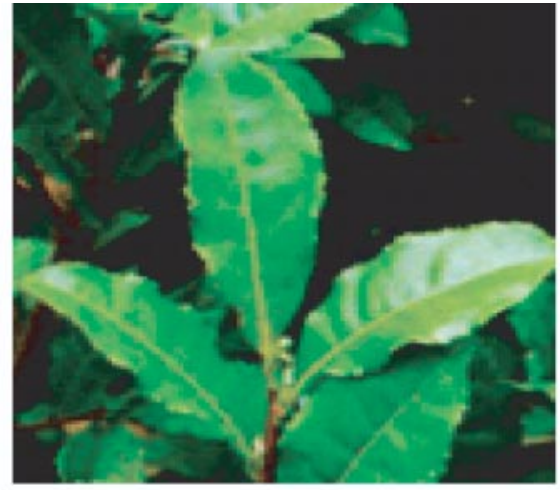

A. Camellia sinensis

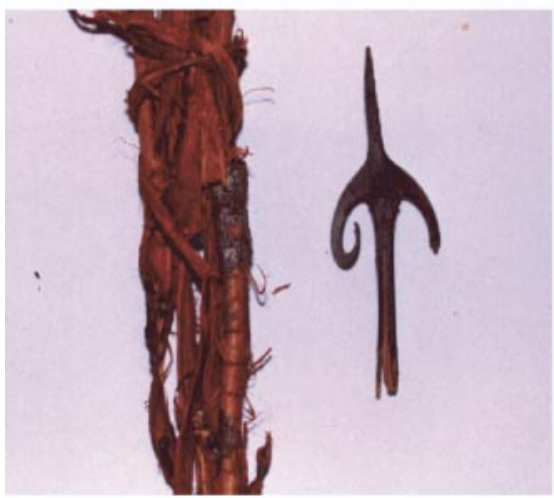

B.2. Uncaria guanensis

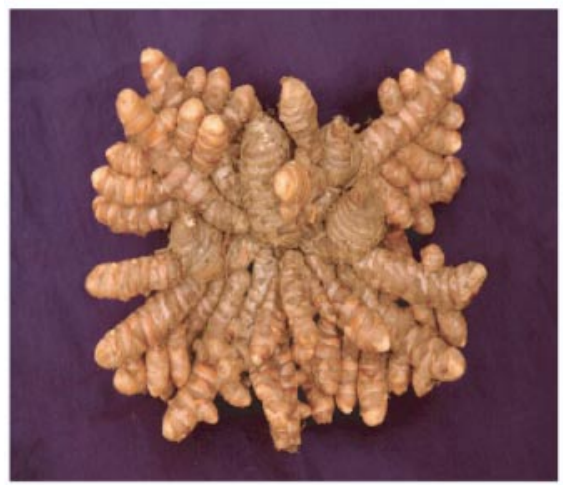

D. Curcuma longa

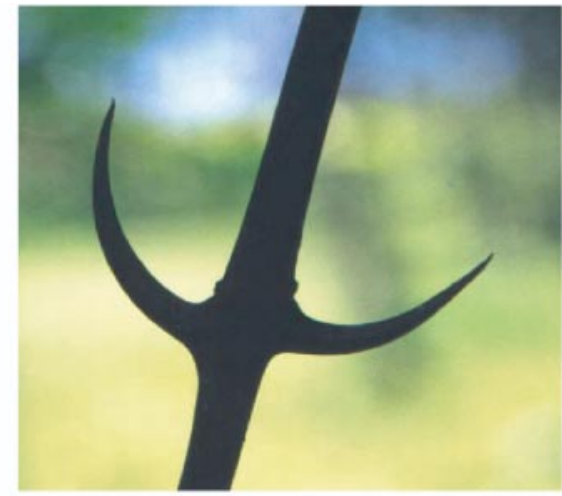

B.1. Uncaria tomentosa

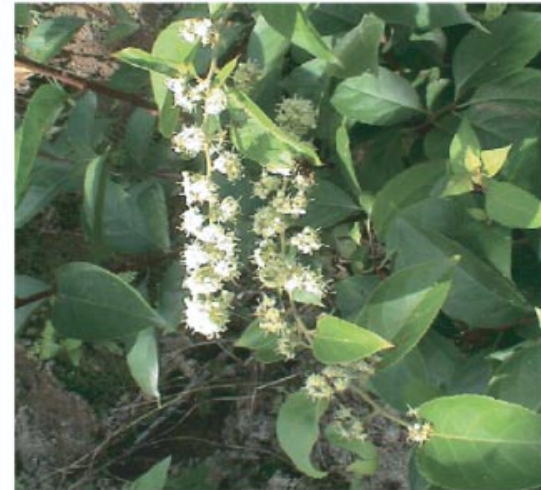

C. Tripterygium wilfordii Hook $F$

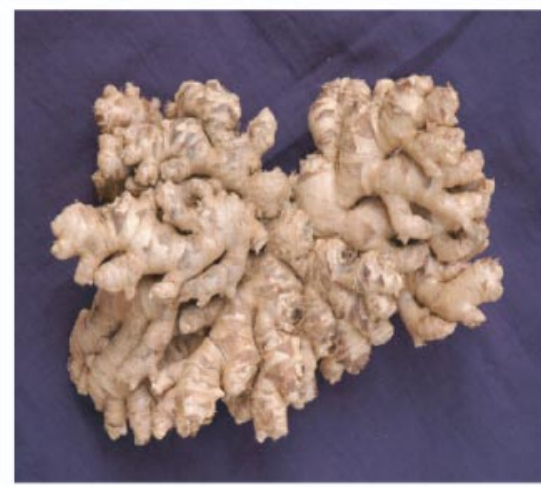

E. Zingiber officinale

Figure 1. Plants and herbs most commonly used in CAM practices for the treatment of rheumatic diseases. [Images courtesy of Dr Hasan Mukhtar, University of Wisconsin-Madison (A); Rainforest Nutrition, Inc., (B.1 and B.2); Dr Xullien Tao, NIAMS/NIH (C); Dr V. A. Parthasarthy, Indian Institute of Spice Research, Kerala, India (D and E).]

(Fig. 1E) since these are most commonly used as therapeutic agents for the treatment of RA and OA.

\section{C. sinensis (green tea)}

Green tea (Fig. 1A) is one of the most commonly consumed beverages in the world with no reported side effects. The established pharmacological properties of green tea are attributed to its high content of polyphenols/catechins, mainly epigallocatechin-3-gallate (EGCG) (31). The potential disease-modifying effect of green tea on arthritis came to light when it was shown that collagen type II-induced arthritis
(CIA) in mice, an animal model of inflammatory polyarthritis, was ameliorated by prophylactic administration of green tea polyphenols (GTPs) in drinking water (32). The reduced CIA incidence and severity was reflected in a marked inhibition of the inflammatory mediators COX2, interferon- $\gamma$ and TNF$\alpha$ in arthritic joints of green tea-fed mice. The activity of neutral endopeptidase, an enzyme capable of breaking peptides at neutral $\mathrm{pH}$ to block their biological actions, was found to be $\sim 7$-fold higher in arthritic joints of non-GTP-fed mice in comparison to non-arthritic joints of unimmunized mice, but only 2 -fold higher in the arthritic joints of GTP-fed mice. Additionally, total immunoglobulins ( $\operatorname{IgG}$ ) and type II collagen-specific 
IgG levels were found to be lower in serum and arthritic joints of GTP-fed mice. The reduction in biochemical markers correlated with the marked reduction of inflammation in the synovium seen on histopathology.

\section{Mechanism of Action}

Several studies have shown that most of the effects of green tea extract are mimicked by its constituent polyphenol EGCG $(31,33)$. Consequently, further studies were conducted using this compound and it was found that in human chondrocytes derived from OA cartilage EGCG inhibited the transcription factor nuclear factor kappaB (NF- $\kappa \mathrm{B})$ in conjunction with IL-1 $\beta$-inducible nitric oxide synthase (iNOS) and COX-2, resulting in reduction of nitric oxide (NO) and prostaglandin E2(PGE2) in vitro $(34,35)$. It has also been shown that EGCG selectively inhibits the IL-1 $\beta$-induced phosphorylation of c-Jun-N-terminal kinase (JNK) p46 isoform resulting in lower levels of phospho-c-Jun and DNA-binding activity of activation protein-1 (AP-1), a transcription factor implicated in the inflammatory response, in human OA chondrocytes (36). This is important since JNK kinase is a prime culprit in inflammatory and degenerative diseases (37-40).

Matrix metalloproteinases (MMPs) are produced by activated chondrocytes and other cell types in an arthritic joint. Physiologically, they take part in remodeling although excessive production in the joint results in cartilage degradation. Among the MMPs, MMP-1 and MMP-13 levels are found to be significantly elevated in both OA and RA arthritic joints $(1,41,42)$. Recent studies have revealed that pretreatment of human OA chondrocytes with EGCG significantly, in a dosedependent manner, inhibited the expression and activities of MMP-1 and MMP-13 (IC50 values 27 and $16.5 \mu \mathrm{M}$, respectively) in vitro (43). It has also been shown that EGCG was equally effective in inhibiting IL-1 $\beta$-induced MMP-1, -3 and -13 in human tendon fibroblasts (44). Also, it was recently shown that catechins from green tea inhibited the degradation of human cartilage proteoglycan and type II collagen, and selectively inhibited the aggrecanases called a disintegrin and metalloproteinase with thrombospondin motifs (ADAMTS)$1,-4$ and $-5(45,46)$. Thus, there is experimental evidence to support further studies to investigate the anti-inflammatory and chondroprotective effects of green tea at the molecular level. With the global availability of green tea, its low cost and proven lack of toxicity, green tea catechins or compounds derived from them could one day be useful as a conventional medicine or as effective adjunct therapies for the treatment of both RA and OA.

\section{Cat's Claw (U. tomentosa, U. guianensis)}

Cat's claw is a Peruvian vine with medicinal properties that are well-documented in alternative medicine literature. Extract of cat's claw has been shown to possess antioxidant, antiinflammatory and immunomodulating properties [reviewed in (47), also see (48)]. Extracts or preparations from the two species $U$. tomentosa (Fig. 1B.1) or U. guianensis (Fig. 1B.2) are interchangeably used to treat various inflammatory and non-inflammatory conditions in the Peruvian medicinal system. The chemical composition of the aqueous extract of $U$. tomentosa vine includes oxindole alkaloids (virtually absent in $U$. guianensis) tannins, quinovic acid, glycosides, flavonoids and sterols (49). The most investigated of the active constituents in $U$. tomentosa extract for immunomodulating and anti-inflammatory effects are pentacyclic oxindole alkaloids, which are reported to induce a yet unknown immune regulating factor (47). However, the antioxidant and antiinflammatory effects of the extracts of $U$. tomentosa and $U$. guianensis appear to be independent of their alkaloid content as in several assays $U$. guianensis was more potent in free radical scavenging and inhibition of TNF- $\alpha$ production by mouse macrophages (50). In another study, Piscoya and co-workers (51) evaluated the safety and side effects of $U$. guianensis extract in patients with $\mathrm{OA}$ of the knee. Pain associated with activities of daily living was significantly reduced, although pain at rest or at night was not reduced during this 4 week trial period. In another study, the use of an extract of cat's claw from the part of the vine that is rich in pentacyclic alkaloids (roots) showed a reduction in the number of painful joints when compared to placebo in patients with RA (by 53.2 versus $24.1 \% ; P=0.044$ ) (52). Since no adverse effects were reported, this small preliminary study demonstrated the relative safety and modest benefit to the tender joint count of a highly purified extract from the pentacyclic chemotype of $U$. tomentosa in patients with active RA taking sulfasalazine or hydroxychloroquine (52).

Several other groups have documented the safety and pharmacological profile of cat's claw in animal models and also showed that cat's claw was non-toxic in in vitro bioassays [(47,50-54) and references therein]. Several standardized extracts of cat's claw are available commercially and different dosages have been recommended for different conditions, but effectiveness of these recommended doses has not been rigorously tested. In some cases, mild nausea may occur upon ingestion of crude extracts or teas (perhaps due to micropulverized bark in some preparations), but other than diarrhea in some cases no other gastrointestinal events have been associated with these herbs $(47,51,52,54)$. Indeed, studies in animal models have documented that cat's claw is protective to the gastrointestinal tract and suggests that the use of cat's claw extract may even protect the gut from the damaging effects of NSAIDs (55). Although, in recommended dosages use of cat's claw is considered non-toxic, and there are no known contraindications or drug interactions, this aspect has not been rigorously investigated. Until the effects of these Peruvian herbs are better known, it is advisable to avoid their use in women attempting pregnancy, during pregnancy and lactation, and for children $<3$ years of age $(47,54)$.

\section{Mechanism of Action}

The antioxidant and anti-inflammatory activity of cat's claw extract was characterized in studies using the murine 
macrophages cell line RAW 264.7. These studies showed that cat's claw extract was effective in inhibiting lipopolysaccharide (LPS)-induced free radical production and subsequent lipid peroxidation in these cell types (55). In addition, the authors also showed that TNF- $\alpha$ production and iNOS expression via NF- $\mathrm{BB}$ expression were also inhibited by the cat's claw extract. Although not yet fully elucidated, the antioxidant and immunomodulating properties of the compounds certainly appear to be important in their anti-inflammatory action. These studies are important enough to support more extensive studies before long-term controlled trials of cat's claw extracts, or active compounds therein, can be initiated in large number of human subjects to determine their long-term efficacy and safety profile.

\section{T. wilfordii Hook F}

T. wilfordii Hook F (TwHF) is a perennial vine-like plant that grows in Southern China and Taiwan and is also known as 'Thunder God Vine' (Fig. 1C). The medicinal extract is derived from the root and has been used for the treatment of various autoimmune and inflammatory diseases including RA, systemic lupus erythematosus, nephritis, psoriasis and asthma for several centuries (56). An ethanol/ethyl acetate extract of TwHF showed therapeutic benefit in patients with treatmentrefractory RA (57). At the dosages used, the TwHF extract was well tolerated by most patients in this study. A prospective, double-blind, placebo-controlled study of TwHF ethanol/ ethyl acetate extracts with RA patients has also been reported (58). With a two-dose regimen, (180 and $360 \mathrm{mg}$ day $^{-1}$ ) used for 20 weeks, patients at the higher dose achieved a rapid ACR-20 response with $50 \%$ of patients improving during the first 4 weeks of treatment.

Both treatment groups showed a significant decrease in the number of tender and swollen joints and improvement in the physician's global assessment. In another phase-I study, eight out of nine patients treated with TwHF extract $(>360 \mathrm{mg}$ day $^{-1}$ ) showed improvements in both clinical manifestations and laboratory findings (58). One patient met American College of Rheumatology criteria for remission. Based on these data it was concluded that the extract of TwHF at dosages up to $570 \mathrm{mg} \mathrm{day}{ }^{-1}$ appeared to be safe, and doses $>360 \mathrm{mg}$ day $^{-1}$ were associated with clinical benefit in patients with RA. In both of these studies, no toxic or adverse effects other than diarrhea were observed in patients receiving the highest dose. Topical application of TwHF was also tested in a randomized, double-blind, placebo-controlled trial using 61 patients with RA and the authors concluded that topical application of TwHF was efficacious in improving ACR-20 score (59).

In these and other studies, the most common side effects of TwHF were vomiting, hair loss, diarrhea, headaches, dryness, abdominal pain and vaginal spotting. TwHF usage can also lead to the development of amenorrhea, which is reversible if present for $<2$ years in patients $<40$ years of age but irreversible in perimenopausal women patients (56).

\section{Mechanism of Action}

The immunosuppressive and anti-inflammatory effects of TwHF are believed to be mediated by one of its biologically active constituent Triptolide (60). In animal studies, triptolide inhibited the CIA in mice and rats $(61,62)$ and markedly suppressed the IL-1 and LPS-induced production of proMMP-1 and proMMP-3 in cultured synovial fibroblasts and mouse macrophages (63). Recent studies showed that triptolide inhibited iNOS gene expression by downregulating NF- $\kappa B$ DNAbinding activity and JNK pathway (64). In other studies, TwHF extract or its active constituent Triptolide were shown to inhibit LPS- and cytokine-induced expression of COX-2, MMP-3 and MMP-13 in articular chondrocytes (65). Triptolide has also recently been shown to inhibit the IL-1, IL-17 and TNF- $\alpha$-induced expression of aggrecanase gene in human chondrocytes (66). An additional mechanism of its antiinflammatory effect may be via suppression of adhesion molecules E-selectin, ICAM-1 and VCAM-1 (67). These and other studies provide strong evidence regarding the scientific basis of the known beneficial effects observed in RA patients, but the molecular mechanism by which TwHF extracts or triptolide inhibit RA disease severity is yet to be elucidated. The above in vitro and other studies support the conclusion that TwHF extract or its biologically active constituent triptolide is efficacious in RA. Its efficacy in OA has not yet been determined but data from in vitro studies (63-66) strongly suggests that TwHF should be evaluated in animal models as a first step for its possible use in the prevention or treatment of OA.

\section{C. longa (turmeric)}

Turmeric is a widely used spice and coloring/flavoring agent that comes from the root of the plant C. longa (Fig. 1D), a member of the Zingaberacea family (68). The FDA classified turmeric among substances 'generally recognized as safe'. In Ayurveda, turmeric has been used for various medicinal conditions including rhinitis, wound healing, common cold, skin infections, liver and urinary tract diseases and as a 'blood purifier' (68-70). Turmeric was found to be effective even when given by different routes including topical, oral or by inhalation, dependent on the intended use. The major constituent of turmeric is curcumin (diferuloylmethane), which constitutes up to $\sim 90 \%$ of total curcuminoid content, with demethoxycurcumin and bis-demethoxycurcumin comprising the remainder (68). In animal studies, oral administration of curcumin to rats decreased the levels of inflammatory glycoprotein, Gp A 72 , with a reduction in paw inflammation (71). Curcumin has also been shown to inhibit the carrageenin-induced paw edema in mice and rats, with an ED50 dose 48 and $100.2 \mathrm{mg} \mathrm{kg}^{-1}$, respectively $(71,72)$. In a double-blinded crossover clinical trial of 18 patients with RA given curcumin (1200 $\mathrm{mg} \mathrm{day}^{-1}$ ) for 2 weeks followed by $300 \mathrm{mg}$ day $^{-1}$ of phenylbutazone for another 2 weeks, respondents showed a significant improvement in morning stiffness, walking time and reduction in joint swelling (73). 


\section{Mechanism of Action}

Curcumin is a non-toxic dietary pigment in turmeric and is potent inhibitor of the common transcription factor $\mathrm{NF}-\kappa \mathrm{B}$ in several cell types (74-76). Other studies have shown that curcumin inhibits/modulates upstream pathways of the arachidonic acid cascade (COX-2 and LOX) by inhibiting the catalytic activities of phospholipases A2, C $\gamma 1$ and D in various cell lines (77-79). In human chondrocytes, curcumin significantly inhibited MMP-3 and MMP-13 gene expression by inhibiting the JNK, AP-1 and NF- $\mathrm{BB}$ pathways (75). Other studies have shown that curcumin blocks LPS and interferon$\gamma$-induced production of $\mathrm{NO}$ and TNF- $\alpha$ in vitro by inhibiting the activation of NF- $\mathrm{BB}$ and AP-1 [reviewed in (68)]. Curcumin also inhibited the incorporation of arachidonic acid into membrane lipids, PGE2 production, leukotriene B4 and leukotriene C4 synthesis, as well as the secretion of collagenase, elastase and hyaluronidase by macrophages (78). Furthermore, IL-1 $\beta$-induced upregulation of MMP-3 was inhibited by curcumin in a time-dependent manner. In addition, IL-1 $\beta$-induced decrease in type II collagen synthesis was also blocked by curcumin treatment. Based on the data obtained it was concluded that curcumin antagonizes crucial catabolic effects of IL-1 $\beta$ signaling that are known to contribute to the pathogenesis of OA. Although not conclusive, but these data clearly show the necessity of additional studies to develop and use optimized doses in randomized, placebocontrolled clinical trials to confirm or refute the reported efficacy of the use of curcumin in OA and RA.

\section{Z. officinale (ginger)}

Ginger, the rhizome of Z. officinale (Fig. 1E), is one of the most common constituents of diets worldwide and is reported to possess antioxidant, anti-inflammatory, antiseptic and carminative properties (80). In Ayurvedic and traditional Sino-Japanese medicine systems, ginger has been used for thousands of years to treat inflammatory and rheumatic diseases. The major constituents of ginger include volatile oils, oleoresin (gingerol), linoleic acid and trace elements such as magnesium, phosphorus and potassium. The pungent phenolic constituent of ginger, [6]-gingerol, inhibited LPS-induced iNOS expression and production of NO and other RNS species in macrophages and blocked peroxynitrite-induced oxidation and nitration reactions in vitro (81). These results suggest that [6]-gingerol is a potent inhibitor of NO synthesis and also an effective protector against peroxynitrite-mediated damage. Another in vitro study showed that ginger extract was effective in inhibiting production of PGE2 and TNF- $\alpha$ and COX-2 expression in human synoviocytes by regulating $\mathrm{NF}-\kappa \mathrm{B}$ activation and degradation of its inhibitor $\mathrm{I} \kappa \mathrm{B} \alpha(82)$. Anti-inflammatory activities of silica gel chromatography fractions of ginger have also been tested using an in vitro PGE2 assay. Results showed that most of the fractions containing gingerols and/or gingerol derivatives were excellent inhibitors of LPS-induced PGE2 production (83). Ginger extract administered daily for 4 weeks, either orally or intraperitoneally caused significant reduction in PGE2 levels in rats (82).

In other studies, ginger alleviates pain and associated symptoms in patients suffering from OA. In a randomized, double-blind, placebo-controlled trial of the effects of ginger extract on knee OA, $63 \%$ of the patients in the ginger extract group experienced reduction in knee pain on standing versus $50 \%$ in the placebo group (84). It was concluded that a highly purified and standardized ginger extract had a statistically significant effect on reducing symptoms of OA of the knee. There was a good safety profile, with mostly mild GI adverse events in the ginger extract group. The beneficial effects of ginger were attributed to its ability to inhibit COX and LOX pathways resulting in the blockade of PGE2 and LTB4 production in affected joints $(77,78)$. More recently, in a randomized, double-blind, placebo-controlled, crossover study in patients with OA, patients in the ginger extract group showed statistically significant effect in the first period of treatment before crossover (85). In a limited study with RA patients, Srivastava and Mustafa (86) reported that ginger was effective in relieving pain and swelling in the joints of seven RA patients. Based on this limited information, it is difficult to determine whether use of ginger or ginger oils will be beneficial in treating of OA or RA. However, these results are strong enough to advocate and support further studies on the effects of ginger in OA and RA in both animal models and clinical studies.

\section{Conclusions}

At present, the current modalities for treating arthritis are symptomatic and have not been shown to either block or reverse the cartilage degradation and joint destruction. This has resulted in heightened interest in the use of CAM therapies for the treatment of arthritis. However, much of the current research is focused on the identification, isolation and characterization of active principle(s) from crude extracts of known medicinal plants or herbs, often overlooking the fact that strong synergism of several constituents in the crude drug may prove more potent and effective than any single purified compound and this may help to nullify the toxic effects of individual constituents (24). This attractive hypothesis encourages further studies but demands rigorous experimentation. Once the underlying molecular mechanism(s) for the observed anti-inflammatory and chondroprotective effects of nutraceuticals are elucidated, their health benefits may be exploited to develop new and better modalities for treating degenerative and inflammatory joint diseases.

\section{Acknowledgements}

This work was supported in part by the USPHS/NIH/NIAMS grant AR-48782 and USPHS/NIH/NCCAM grant AT-02258. 


\section{References}

1. Malemud CJ, Islam N, Haqqi TM. Pathophysiological mechanisms in osteoarthritis lead to novel therapeutic strategies. Cells Tissues Organs 2003;174:34-48.

2. Center for Disease Control and Prevention. Prevalence and impact of chronic joint symptoms-seven states, 1996. MMWR Morb Mortal Wkly Rep 1998;47:345-51.

3. Lawrence RC, Helmick CG, Arnett FC, Deyo RA, Felson DT, Giannini EH, et al. Estimates of the prevalence of arthritis and selected musculoskeletal disorders in the United States. Arthritis Rheum 1998;41: 778-99.

4. Haqqi TM, Anthony DD, Malemud CJ. Chondrocytes. In: Toskos GC (ed). Current Molecular Medicine: Principles of Molecular Rheumatology. Totowa, NJ: Humana Press Inc., 2000;267-77.

5. Goldring MB. The role of cytokines as inflammatory mediators in osteoarthritis: lessons from animal models. Connect Tissue Res 1999;40: $1-11$.

6. Westacott CI, Sharif M. Cytokines in osteoarthritis: mediators or markers of joint destruction. Semin Arthritis Rheum 1996;25:254-72.

7. Goldring MB. Osteoarthritis and cartilage: the role of cytokines. Curr Rheumatol Rep 2000;2:459-65.

8. Firestein GS. Mechanisms of tissue destruction and cellular activation in rheumatoid arthritis. Curr Opin Rheumatol 1992;4:348-54.

9. Harris ED, Jr. Rheumatoid arthritis. Pathophysiology and implications for therapy. N Engl J Med 1990;322:1277-89.

10. Gabriel SE. The epidemiology of rheumatoid arthritis. Rheum Dis Clin North Am 2001;27:269-81.

11. Gabriel SE, Crowson CS, O'Fallon WM. Comorbidity in arthritis. $J$ Rheumatol 1999;26:2475-9.

12. Mikuls TR, Saag KG. Comorbidity in rheumatoid arthritis. Rheum Dis Clin North Am 2001;27:283-303.

13. Maradit-Kremers H, Nicola PJ, Crowson CS, Ballman KV, Gabriel SE. Cardiovascular death in rheumatoid arthritis: a population-based study. Arthritis Rheum 2005;52:722-32.

14. Firestein GS. Evolving concepts of rheumatoid arthritis. Nature 2003;423: 356-61.

15. Firestein GS, Manning AM. Signal transduction and transcription factors in rheumatic disease. Arthritis Rheum 1999;42:609-21.

16. Pope RM. Apoptosis as a therapeutic tool in rheumatoid arthritis. Nat Rev Immunol 2002;2:527-35.

17. Koch AE. Chemokines and their receptors in rheumatoid arthritis. Future targets? Arthritis Rheum 2005;52:710-21.

18. Pincus T, Sokka T, Kautiainen H. Patients seen for standard rheumatoid arthritis care have significantly better articular, radiographic, laboratory, and functional status in 2000 than in 1985. Arthritis Rheum 2005;52: 1009-19.

19. Feldman M, Steinman L. Design of effective immunotherapy for human autoimmunity. Nature 2005;435:612-19.

20. Arend WP, Dayer JM. Inhibition of the production and effects of interleukin-1 and tumor necrosis factor- $\alpha$ in rheumatoid arthritis. Arthritis Rheum 1995;38:151-60.

21. Feldman M, Maini RN. Anti-TNF- $\alpha$ therapy of rheumatoid arthritis: what have we learned. Annu Rev Immunol 2001;19:163-96.

22. Brown SL, Greene MH, Gershon SK, Edwards ET, Braun MM. Tumor necrosis factor antagonist therapy and lymphoma development: twentysix cases reported to the Food and Drug Administration. Arthritis Rheum 2002;46:3151-8.

23. Baghai M, Osmon DR, Wolk DM, Wold LE, Haidukewych GJ, Matteson EL. Fatal sepsis in a patient with rheumatoid arthritis treated with etanercept. Mayo Clin Proc 2001;76:653-6.

24. Engel LW, Straus SE. Development of therapeutics: opportunities within complementary and alternative medicine. Nat Rev 2002;1:229-37.

25. Jacobs JWG, Rasker JJ, Bijlsma JWJ. Alternative medicine in rheumatology: threat or challenge. Clin Exp Rheumatol 2001;19:117-9.

26. Huxtable RJ. The pharmacology of extinction. J Ethnopharmacol 1992;37:1-11.

27. Borchers AT, Keen CL, Stern JS, Gershwin ME. Inflammation and native American medicine: the role of botanicals. Am J Clin Nutr 2000;72: 339-47.

28. Brune K. Safety of anti-inflammatory treatment-new ways of thinking. Rheumatology (Oxford) 2004;43S:16-20.

29. Soeken KL, Miller SA, Ernst E. Herbal medicines for the treatment of rheumatoid arthritis: a systematic review. Rheumatology 2003;42:652-9.
30. Kessler RC, Davis RB, Foster DF, Van Rompay MI, Walters EE, Wilkey SA, et al. Long-term trends in the use of complementary and alternative medical therapies in the United States. Ann Intern Med 2001;135:262-8.

31. Siddiqui IA, Afaq F, Adhami VM, Ahmad N, Mukhtar H. Antioxidants of the beverage tea in promotion of human health. Antioxid Redox Signal 2004;6:571-82.

32. Haqqi TM, Anthony DD, Gupta S, Ahmad N, Lee M-S, Kumar GK, et al. Prevention of collagen-induced arthritis in mice by a polyphenolic fraction from green tea. Proc Natl Acad Sci USA 1999;96:4524-9.

33. Curtis CL, Harwood JL, Dent CM, Caterson B. Biological basis for the benefit of nutraceutical supplementation in arthritis. Drug Discov Today 2004;9:165-72.

34. Singh R, Ahmed S, Islam N, Goldberg VM, Haqqi TM. Epigallocate chin3-gallate inhibits interleukin-1 $\beta$-induced expression of nitric oxide synthase and production of nitric oxide in human osteoarthritis chondrocytes: suppression of nuclear factor- $\kappa \mathrm{B}$ (NFKB p65) activation by inhibiting IкB- $\alpha$ degradation. Arthritis Rheum 2002;46:2079-86.

35. Ahmed S, Rahman A, Hasnain A, Lalonde M, Goldberg VM, Haqqi TM. Green tea polyphenol epigallocatechin-3-gallate inhibits the IL-1ßinduced activity and expression of cyclooxygenase- 2 and nitric oxide synthase- 2 in human chondrocytes. Free Radic Biol Med 2002;33:1097-105.

36. Singh R, Ahmed S, Malemud CJ, Goldberg VM, Haqqi TM. Epigallocatechin-3-gallate selectively inhibits interleukin-1 $\beta$-induced activation of mitogen activated protein kinase subgroup c-jun N-terminal kinase (JNK) in human osteoarthritis chondrocytes. J Orthop Res 2003;21:102-9.

37. Clancy R, Rediske J, Koehne C, Stoyanovsky D, Amin A, Attur M, et al. Activation of stress-activated protein kinase in osteoarthritic cartilage: evidence for nitric oxide dependence. Osteoarthritis Cartilage 2001;9: 294-9.

38. Vincenti MP, Brinckerhoff CE. The potential of signal transduction inhibitors for the treatment of arthritis: is it all just JNK? J Clin Invest 2001; 108:181-3.

39. Ruckle T, Biamonte M, Grippi-Vallotton T, Arkinstall S, Cambet Y, Camps M, et al. Design, synthesis, and biological activity of novel, potent, and selective (benzoylaminomethyl) thiophene sulfonamide inhibitors of c-Jun-N-terminal kinase. J Med Chem 2004;47:6921-34.

40. Bogoyevitch MA, Boehm I, Oakley A, Ketterman AJ, Barr RK. Targeting the JNK MAPK cascade for inhibition: basic science and therapeutic potential. Biochim Biophys Acta 2004;1697:89-101.

41. Ishiguro N, Kojima T, Poole AR. Mechanism of cartilage destruction in osteoarthritis. Nagoya J Med Sci 2002;65:73-84.

42. Iannone F, Lapadula G. The pathophysiology of osteoarthritis. Aging Clin Exp Res 2003;15:364-72.

43. Ahmed S, Lalonde M, Wang N, Goldberg VM, Haqqi TM. Green tea polyphenol epigallocatechin-3-gallate (EGCG) differentially inhibits interleukin-1 $\beta$-induced expression of matrix metalloproteinases- 1 and -13 in human chondrocytes. J Pharmacol Exp Ther 2004;308:767-73.

44. Corps AN, Curry VA, Buttle DJ, Hazleman BL, Riley GP. Inhibition of interleukin-1beta-stimulated collagenase and stromelysin expression in human tendon fibroblasts by epigallocatechin gallate ester. Matrix Biol 2004;23:163-9.

45. Adcocks C, Collin P, Buttle DJ. Catechins from green tea (Camellia sinensis) inhibit bovine and human cartilage proteoglycan and type II collagen degradation in vitro. $J$ Nutr 2002;132:341-6.

46. Vankemmelbeke MN, Jones GC, Fowles C, Ilic MZ, Handley CJ, Day AJ, et al. Selective inhibition of ADAMTS-1, -4 and -5 by catechin gallate esters. Eur J Biochem 2003;270:2394-403.

47. Williams JE. Review of antiviral and immunomodulating properties of plants of the Peruvian rainforest with a particular emphasis on una de Gato and Sangre de Grado. Altern Med Rev 2001;6:567-79.

48. Sandoval-Chacon M, Thompson JH, Zhang XJ, Mannick EE, Sadowska-Krowicka H, Charbonnet RM, et al. Antiinflammatory actions of cat's claw: the role of NF-кB. Aliment Pharmacol Ther 1998;12: 1279-89.

49. Muhammad I, Dunbar D, Khan R, Gunzera M, Khan IA. Investigation on uña de gato I. 7-deoxyloganic acid and 15N NMR spectroscopic studies on pentacyclic oxindole alkaloids from Uncaria tomentosa. Phytochemistry 2001;57:781-5.

50. Sandoval M, Okuhama NN, Zhang XJ, Condezo LA, Angeles FM, Musah RM, et al. Anti-inflammatory and antioxidant activities of cat's claw (Uncaria tomentosa and Uncaria guianensis) are independent of their alkaloid content. Phytomedicine 2002;9:325-37. 
51. Piscoya J, Rodriguez Z, Bustamante SA, Okuhama NN, Miller MJ, Sandoval M. Efficacy and safety of freeze-dried cat's claw in osteoarthritis of the knee: mechanisms of action of the species Uncaria guianensis. Inflamm Res 2001;50:442-8.

52. Mur E, Hartig F, Eibl G, Schirmer M. Randomized double blind trial of an extract from the pentacyclic alkaloid-chemotype of Uncaria tomentosa for the treatment of rheumatoid arthritis. J Rheumatol 2002;29:656-8.

53. Santa Maria A, Lopez A, Diaz MM, Alban J, Galan de Mera A, Vicente Orellana JA, et al. Evaluation of the toxicity of Uncaria tomentosa by bioassays in vitro. J Ethnopharmacol 1997;57:183-7.

54. Fetrow CW, Avila JR. Professionals Handbook of Complementary and Alternative Medicines. Springhouse, PA: Springhouse, 1999.

55. Sandoval M, Charbonnet RM, Okuhama NN, Roberts J, Krenova Z, Trentacosti AM, et al. Cat's claw inhibits TNFalpha production and scavenges free radicals: role in cytoprotection. Free Radic Biol Med 2000;29: $71-8$.

56. Tao X, Lipsky PE. The Chinese anti-inflammatory and immunosuppressive herbal remedy Tripterygium wilfordii Hook F. Rheum Dis Clin North Am 2000;57:1221-7.

57. Tao X, Younger J, Fan FZ, Wang B, Lipsky PE. Benefit of an extract of Tripterygium wilfordii Hook $\mathrm{F}$ in patients with rheumatoid arthritis. Arthritis Rheum 2002;46:1735-43.

58. Tao X, Cush JJ, Garret M, Lipsky PE. A phase I study of ethyl acetate extract of the chinese antirheumatic herb Tripterygium wilfordii hook $\mathrm{F}$ in rheumatoid arthritis. J Rheumatol 2001;28:2160-7.

59. Cibere J, Deng Z, Lin Y, Ou R, He Y, Wang Z, et al. A randomized double blind, placebo controlled trial of topical Tripterygium wilfordii in rheumatoid arthritis: reanalysis using logistic regression analysis. J Rheumatol 2003;30:465-7.

60. Qui D, Kao PN. Immunosuppressive and anti-inflammatory mechanisms of triptolide, the principal active diterpenoid from the Chinese medicinal herb Tripterygium wilfordii Hook F. Drugs R D 2003;4:1-18.

61. Gu WZ, Brandwein SR. Inhibition of type II collagen-induced arthritis in rats by triptolide. Int J Immunopharmacol 1998;20:389-400.

62. Gu WZ, Brandwein SR, Banerjee S. Inhibition of type II collagen induced arthritis in mice by an immunosuppressive extract of Tripterygium wilfordii Hook f. J Rheumatol 1992;19:682-8.

63. Lin N, Sato T, Ito A. Triptolide, a novel diterpenoid triepoxide from Tripterygium wilfordii Hook. f, suppresses the production and gene expression of pro-matrix metalloproteinases 1 and 3 and augments those of tissue inhibitors of metalloproteinases 1 and 2 in human synovial fibroblasts. Arthritis Rheum 2001;44:2193-200.

64. Wang B, Ma L, Tao X, Lipsky PE. Triptolide, an active component of the Chinese herbal remedy Tripterygium wilfordii Hook F, inhibits production of nitric oxide by decreasing inducible nitric oxide synthase gene transcription. Arthritis Rheum 2004;50:2995-3003.

65. Sylvester J, Liacini A, Li WQ, Dehnade F, Zafarullah M. Tripterygium wilfordii Hook $\mathrm{F}$ extract suppresses proinflammatory cytokine-induced expression of matrix metalloproteinase genes in articular chondrocytes by inhibiting activating protein-1 and nuclear factor-kappaB activities. Mol Pharmacol 2001;59:1196-205.

66. Liacini A, Sylvester J, Zafarullah M. Triptolide suppresses proinflammatory cytokine-induced matrix metalloproteinase and aggrecanase-1 gene expression in chondrocytes. Biochem Biophys Res Commun 2005;327: $320-7$.

67. Chang DM, Kuo SY, Lai JH, Chang ML. Effects of anti-rheumatic herbal medicines on cellular adhesion molecules. Ann Rheum Dis 1999;58: 366-71.

68. Aggarwal BB, Shishodia S. Suppression of the nuclear factor- $\mathrm{\kappa B}$ activation pathway by spice-derived phytochemicals: reasoning for seasoning. Ann NY Acad Sci 2004;1030:434-41.
69. Chainani-Wu N. Safety and anti-inflammatory activity of curcumin: a component of turmeric (Curcuma longa). J Altern Complement Med 2003;9:161-8

70. Srivastava KC, Bordia A, Verma SK. Curcumin, a major component of food spice turmeric (Curcuma longa) inhibits aggregation and alters eicosanoid metabolism in human blood platelets. Prostaglandins Leukot Essent Fatty Acids 1995;52:223-7.

71. Joe B, Rao UJ, Lokesh BR. Presence of an acidic glycoprotein in the serum of arthritic rats: modulation by capsaicin and curcumin. Mol Cell Biochem 1997;169:125-34.

72. Mukhopadhyay A, Basu N, Ghatak N, Gujral PK. Anti-inflammatory and irritant activities of curcumin analogues in rats. Agents Actions 1982;12: 508-15.

73. Deodhar SD, Sethi R, Srimal RC. Preliminary studies on antirheumatic activity of curcumin. Ind J Med Res 1980;71:632-4.

74. Ranjan D, Chen C, Johnston TD, Jeon H, Nagabhushan M. Curcumin inhibits mitogen stimulated lymphocyte proliferation, NFkappaB activation, and IL-2 signaling. J Surg Res 2004;121:171-7.

75. Liacini A, Sylvester J, Li WQ, Zafarullah M. Inhibition of interleukin1stimulated MAP kinases, activating protein-1 (AP-1) and nuclear factor kappa B (NF-kB) transcription factors down-regulates matrix metalloproteinase gene expression in articular chondrocytes. Matrix Biol 2002;21: 251-62.

76. Schulze-Tanzil G, Mobasheri A, Sendzik J, John T, Shakibaei M. Effects of curcumin (diferuloylmethane) on nuclear factor- $\mathrm{\kappa B}$ signaling in interleukin-1B-stimulated chondrocytes. Ann NY Acad Sci 2004;1030:578-86.

77. Hong J, Bose M, Ju J, Ryu JH, Chen X, Sang S, et al. Modulation of arachidonic acid metabolism by curcumin and related beta diketone derivatives: effects on cytosolic phospholipase $\mathrm{A}(2)$, cyclooxygenases and 5-lipoxygenase. Carcinogenesis 2004;25:1671-9.

78. Wallace JM. Nutritional and botanical modulation of the inflammatory cascade eicosanoids, cyclooxygenases, and lipoxygenases - as an adjunct in cancer therapy. Integr Cancer Ther 2002;1:7-37.

79. Frondoza CG, Sohrabi A, Polotsky A, Phan PV, Hungerford DS, Lindmark L. An in vitro screening assay for inhibitors of proinflammatory mediators in herbal extracts using human synoviocyte cultures. In Vitro Cell Dev Biol Anim 2004;40:95-101.

80. Afzal M, Al-Hadidi D, Menon M, Pesek J, Dhami MS. Ginger: an ethnomedical, chemical and pharmacological review. Drug Metabol Drug Interact 2001;18:159-90.

81. Ippoushi K, Azuma K, Ito H, Horie H, Higashio H. [6]-Gingerol inhibits nitric oxide synthesis in activated $\mathbf{J} 774.1$ mouse macrophages and prevents peroxynitrite-induced oxidation and nitration reactions. Life Sci 2003;73: 3427-37.

82. Thomson M, Al-Qattan KK, Al-Sawan SM, Alnaqeeb MA, Khan I, Ali M. The use of ginger (Zingiber officinale Rosc.) as a potential antiinflammatory and antithrombotic agent. Prostaglandins Leukot Essent Fatty Acids 2002;67:475-8.

83. Jolad SD, Lantz RC, Solyom AM, Chen GJ, Bates RB, Timmermann BN. Fresh organically grown ginger (Zingiber officinale): composition and effects on LPS-induced PGE2 production. Phytochemistry 2004;65: 1937-54.

84. Altman RD, Marcussen KC. Effects of a ginger extract on knee pain in patients with osteoarthritis. Arthritis Rheum 2001;44:2531-8.

85. Bliddal H, Rosetzsky A, Schlichting P, Weidner MS, Andersen LA, Ibfelt $\mathrm{HH}$, et al. A randomized, placebo-controlled, cross-over study of ginger extracts and ibuprofen in osteoarthritis. Osteoarthritis Cartilage 2000;8:9-12.

86. Srivastava KC, Mustafa T. Ginger (Zingiber officinale) in rheumatism and musculoskeletal disorders. Med Hypotheses 1992;39:342-8.

Received Feburary 4, 2005; accepted July 24, 2005 


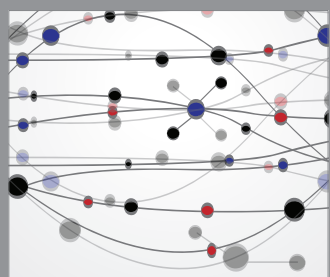

The Scientific World Journal
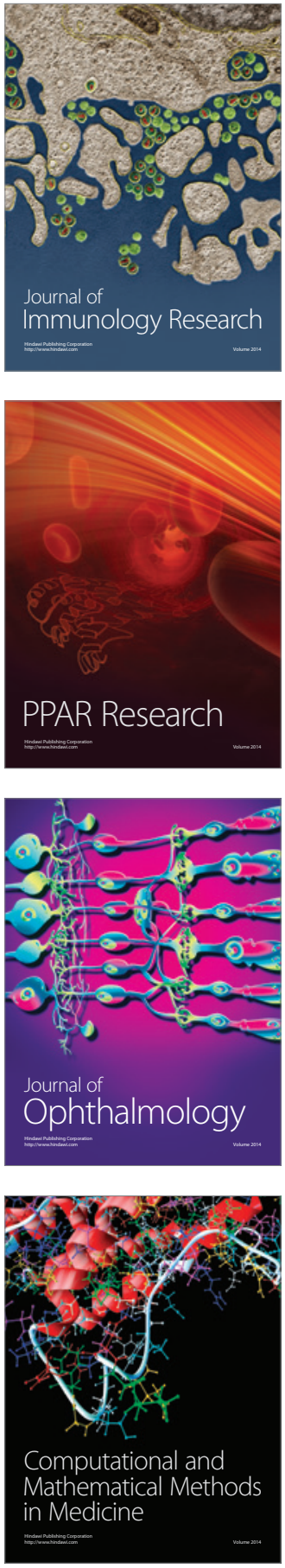

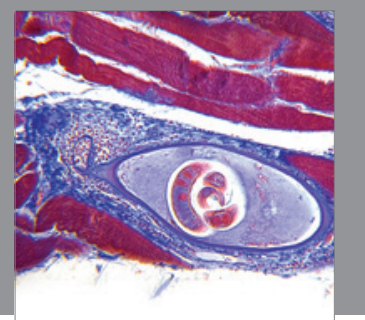

Gastroenterology

Research and Practice
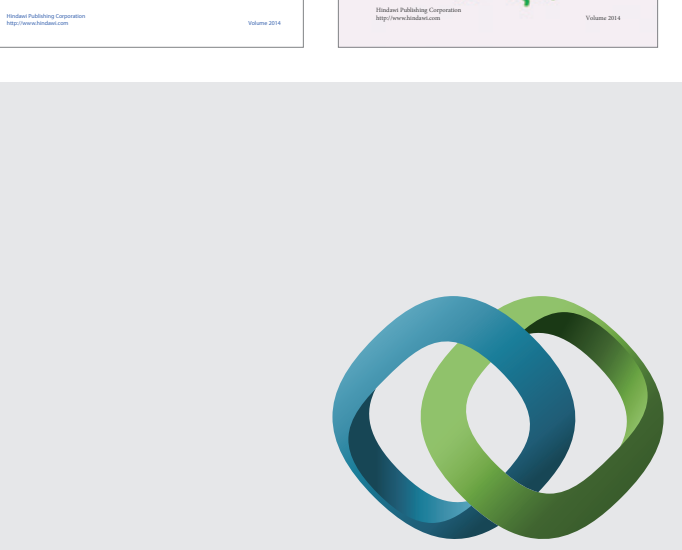

\section{Hindawi}

Submit your manuscripts at

http://www.hindawi.com
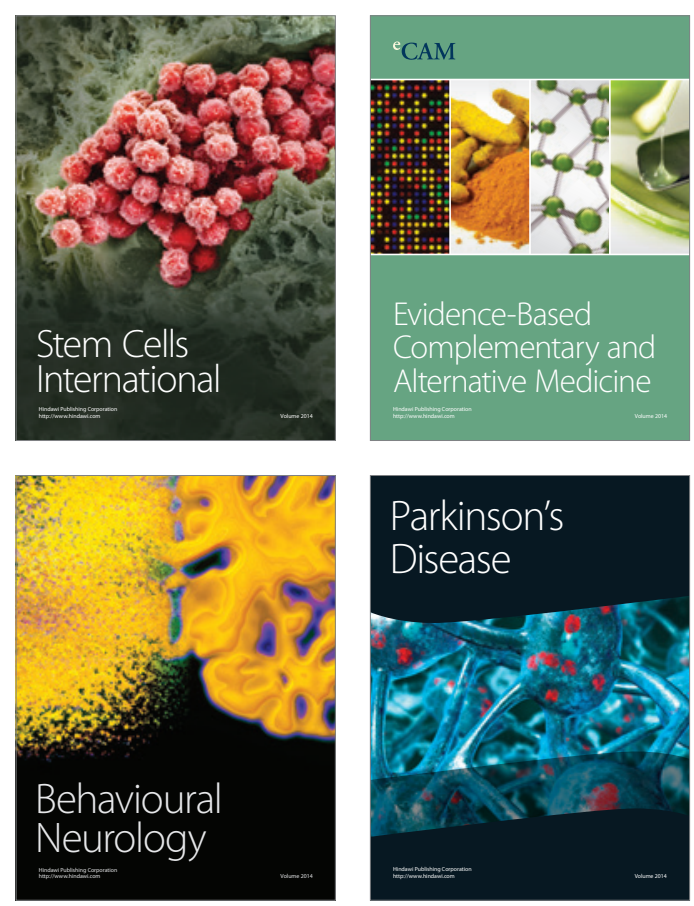

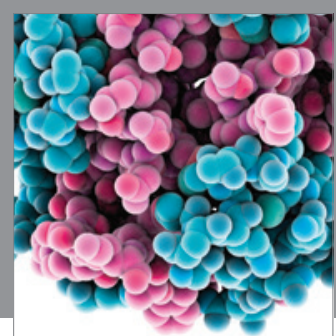

Journal of
Diabetes Research

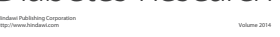

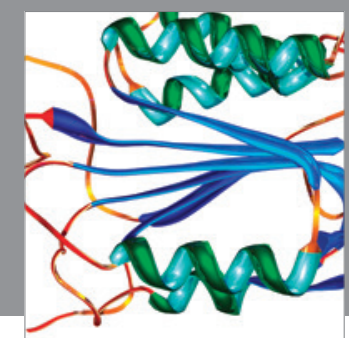

Disease Markers
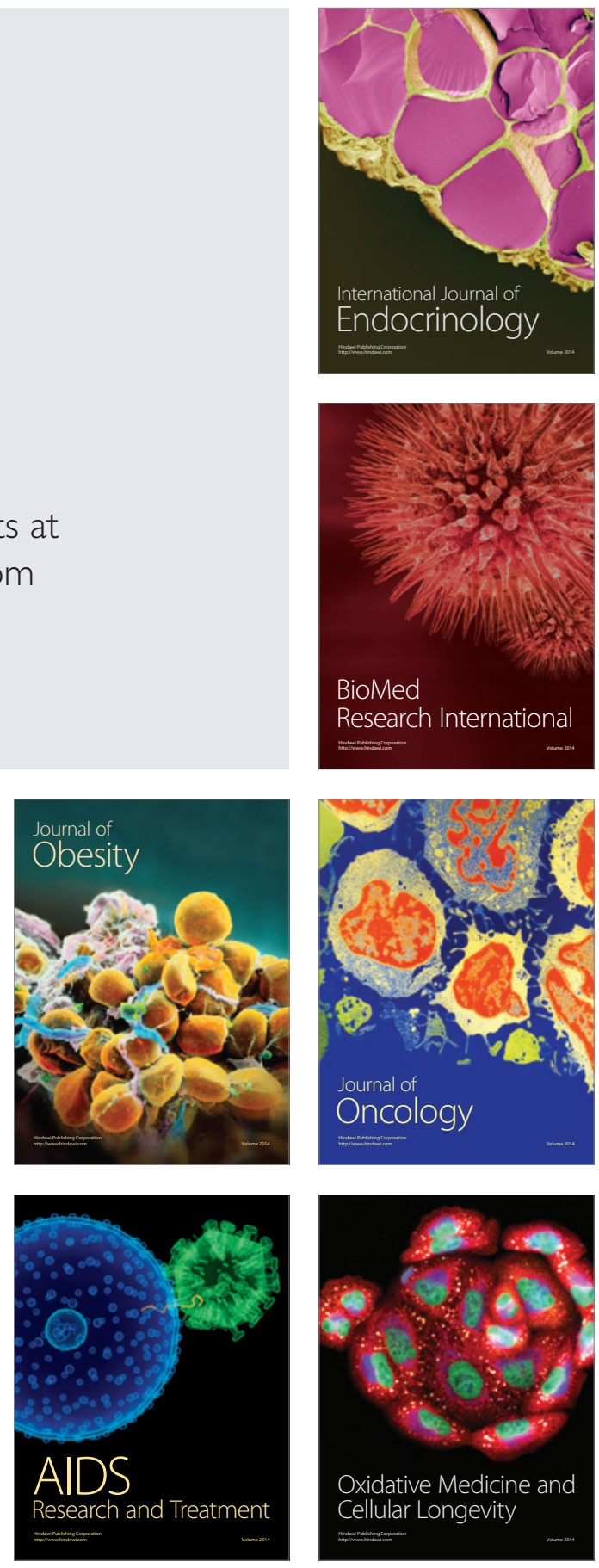